\title{
Family history of cancer and germline BRCA2 mutations in sporadic exocrine pancreatic cancer
}

\author{
F X Real, N Malats, G Lesca, M Porta, S Chopin, G M Lenoir, O Sinilnikova for the \\ PANKRAS II Study Group
}

Gut 2002;50:653-657

See end of article for authors' affiliations

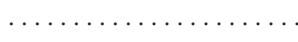

Correspondence to: F X Real, Unitat de Biologia Cel.lular i Molecular, Institut Municipal d'Investigació Mèdica Universitat Pompeu Fabra, carrer del Dr Aiguader, 80, 08003-Barcelona, Spain; preal@imim.es

Accepted for publication 17 July 2001

\begin{abstract}
Background: Hereditary factors have been reported in 5-10\% of cases with exocrine pancreatic cancer and recent data support a role for BRCA2.

Aims: We have studied the prevalence of germline BRCA2 mutations in two groups of patients with exocrine pancreatic cancer from an unselected series in Spain: group A included 24 cases showing familial aggregation of cancer and group B included 54 age, sex, and hospital matched cases without such evidence.

Methods: Information was obtained by interview of patients and was validated by a telephone interview with a structured questionnaire. In patients from group $A,>80 \%$ of the coding sequence of $B R C A 2$ was analysed; in patients from group $B$, the regions in which germline BRCA2 mutations have been described to be associated with pancreatic cancer were screened.

Results: Telephone interviews led to reclassification of $7 / 54$ cases (13\%). Familial aggregation of cancer was found in 24/165 cases (14.5\%); six patients had a first degree relative with pancreatic cancer $(3.6 \%)$ and nine patients had relatives with breast cancer. Germline BRCA2 mutations were not identified in any patient from group $A(0 / 23)$. Among group $B$ cases, one germline variant (T5868G>Asn 1880Lys) was found in a 59 year old male without a family history of cancer. The 6174 delT mutation was not found in any of the 71 cases analysed.

Conclusions: The overall prevalence of BRCA2 mutations among patients with pancreatic cancer in Spain is low and the 6174delT mutation appears to be very infrequent. Our data do not support screening patients with cancer of the pancreas for germline BRCA2 mutations to identify relatives at high risk of developing this tumour.
\end{abstract}

$\mathrm{E}_{\mathrm{b}}$ xocrine pancreatic cancer (EPC) is a leading cause of cancer death in the Western world and little progress has been made in its prevention and management in the past 30 years. The only chance of cure is radical surgery, when this is feasible, but two year survival for patients with tumours $<2$ $\mathrm{cm}$ in diameter is only $20 \%{ }^{1}$ It is most likely that a combination of genetic and environmental or lifestyle factors contribute to the development of this tumour. ${ }^{2}$ Therefore, primary and secondary prevention are crucial to control EPC.

Familial aggregation of pancreatic cancer, suggesting the involvement of genetic factors, has been reported in $5-10 \%$ of cases. ${ }^{4-8}$ Little is known of the genetic susceptibility to pancreatic cancer. EPC can occur in the context of the Li-Fraumeni and hereditary non-polyposis colon cancer syndromes. ${ }^{4}$ Germline mutations in the pl6 $6^{\mathrm{INK4A}}$ tumour suppressor gene have been reported exclusively in individuals with EPC belonging to families with familial atypical mole and malignant melanoma syndrome (FAMMM). ${ }^{10}$ In addition, recent data support the contention that germline and somatic $B R C A 2$ mutations may contribute to EPC: a major step towards isolation of BRCA2 was identification of a homozygous deletion encompassing $\mathrm{l} \mathrm{cM}$ at chromosome $13 \mathrm{ql} 2$ in the tumour of a patient with EPC. ${ }^{11}$ In addition, an excess of EPC has been reported among members of breast cancer families associated with BRCA2 mutations, ${ }^{12-14}$ and BRCA2 germline mutations have been reported among individuals with apparently sporadic EPC. ${ }^{15-17}$

To date, studies have reported on mainly North American subjects with breast cancer or EPC. The BRCA2 6174delT mutation, a founder ancestral mutation in the Ashkenazi Jewish population, appears to be involved in a substantial proportion of pancreatic cancer cases analysed. ${ }^{15-17}$ To gain additional insight into the possible role of germline BRCA2 mutations in EPC, we studied two groups of pancreatic cancer patients, differing on the basis of their family history of cancer. They were obtained from an unselected series of EPC cases recruited to a multicentre study in Spain. For cases showing familial aggregation of cancer, $>80 \%$ of the coding sequence was analysed; for cases without such a history, only previously described BRCA2 mutations in patients with EPC were studied as it is generally thought that these cancer cases are less likely to be genetically predisposed.

\section{PATIENTS AND METHODS \\ PANKRAS II study}

The study included all subjects $(n=602)$ in whom a diagnosis of EPC, extrahepatic biliary system cancer, or chronic pancreatitis was suspected, in five hospitals in Eastern Spain between February 1992 and February 1995. Detailed information on the patient population has been reported elsewhere. ${ }^{18-20}$ All patients gave informed consent to participate in the study. After evaluation by a panel of experts, a diagnosis of EPC was reached by consensus in 185 cases. The other diagnoses included: non-malignant diseases of the pancreas $(n=166$, including 119 chronic pancreatitis), extrahepatic biliary system cancer $(n=128)$, benign biliary disorders $(n=54)$, other benign pathologies $(n=22)$, and other malignancies $(n=47)$. The detailed strategy for diagnostic validation has also been previously reported. ${ }^{19-21}$ Clinical and

Abbreviations: DHPLC, denaturing high performance liquid chromatography; EPC, exocrine pancreatic cancer; FAMMM, familial atypical mole and malignant melanoma syndrome; PCR, polymerase chain reaction; PTT, protein truncation test. 
diagnosis related information was obtained from medical records. Information on lifestyle factors, diet, occupational exposures, and family history of cancer was obtained by personal interview with the patient in $89 \%$ of cases. ${ }^{18}$

From this series, two sets of cases with EPC were selected for the study. Group A included 22 patients who fulfilled the following criteria: (1) a history of one or more first degree relatives with pancreatic or breast cancer or (2) a history of cancer in two or more first degree relatives, regardless of tumour site. Group B included 56 EPC cases who were matched for sex, age ( \pm 5 years; exceptionally \pm 10 years when a better match was not available), and hospital to cases from group A, and who did not fulfill the criteria of familial cancer aggregation. To improve the validity of data on familial aggregation of cancer, a relative was contacted by telephone and the most appropriate next of kin was identified on the basis of her/his knowledge of the family's past medical history. This person was contacted to confirm the information available on the family history of cancer. A structured questionnaire was specifically designed to obtain information on family history of cancer and on pancreas related diseases. A pedigree was established to help the next of kin and the interviewer to collect data. The mean duration of the interview was 41 minutes.

\section{BRCA2 mutation analysis}

DNA was extracted from peripheral blood lymphocytes isolated by Ficoll density gradient centrifugation using TriReagent (Molecular Research Center, Inc., Cincinnati, Ohio, USA) following the manufacturer's instructions. When leucocyte DNA was not available, DNA was isolated from paraffin embedded normal tissue samples. A variety of techniques were used to identify BRCA2 mutations, all of which have been validated in our laboratory and in other studies.

For patients in group A, exons 10 and 11 were studied using the protein truncation test (PTT), performed as described elsewhere, ${ }^{22}$ except that the following primers were used for screening of exon 11: PTT11-1F, TTGCATTCTTCTGTGAAAAG; PTT11-1R, TATCAGTTGGCATTTATTATTTT; PTT11-2F, TCC AAGCAGGATTTTAATTCA; PTT11-2R, TGGCACCACAGTCTCA ATAG; PTT11-3F, GTTAAACACAAAATACTGAAAG; PTT11-3R, TGAAGCTTCCCTATACTACAT; PTT11-4F, CCTGCATTTAGGAT AGCCAG; and PTTIl-4R, AGCATACCAAGTCTACTGAATA AAC. A sample of the polymerase chain reaction (PCR) product $(1 \mu \mathrm{g})$ was added to the TnT/T7 coupled reticulocyte lysate system (Promega, Madison, Wisconsin, USA), the synthesised ${ }^{35} \mathrm{~S}$-Met labelled proteins were separated using sodium dodecyl sulphate-polyacrylamide gel electrophoresis, and dried gels were exposed to autoradiographic films for 12-18 hours. The remaining 24 exons with their corresponding intronic splice-junction sites, as well as the splice junction sequences of exons 10 and 11 , were screened by heteroduplex analysis, as previously described. ${ }^{22}{ }^{33} \mathrm{P}$-dATP labelled PCR products were denatured at $95^{\circ} \mathrm{C}$ for five minutes and cooled to room temperature over at least 30 minutes to induce heteroduplex formation. DNA was electrophoresed through $1 \times \mathrm{MDE}$ gel (FMC Bioproducts) at 300-600 V for 14 hours using a vertical gel electrophoresis apparatus. Gels were dried and exposed to Kodak BioMax MR film and all variant bands were sequenced using the USB PCR product sequencing kit.

DNA from the five additional patients who were reclassified, and included in group $\mathrm{A}^{\text {val }}$ on the basis of the validation interview, was analysed using a different strategy. Exons 10 and 11 were screened using the heteroduplex technique, as described above. The remaining 24 exons were studied using denaturing high performance liquid chromatography (DHPLC) and an automated instrumentation WAVE DNA fragment analysis system (Transgenomic, Omaha, Nebraska, USA). Briefly, 3-10 $\mu$ of PCR product, containing about $50 \mathrm{ng}$ of amplified DNA, was denatured for three minutes at $95^{\circ} \mathrm{C}$ and then gradually reannealed by decreasing the temperature to $65^{\circ} \mathrm{C}$ over a period of 30 minutes. PCR products were then eluted with a linear acetonitrile gradient adjusted according to the size of the PCR fragment, at a flow rate of $0.9 \mathrm{ml} / \mathrm{min}$ and at a denaturing temperature identified with the help of a DHPLC melting algorithm (available at http:// insertion.stanford.edu/cgi-bin/melt.html). Under conditions of partial heat denaturation and acetonitrile gradient, heteroduplexes formed in PCR samples carrying sequence variations display reduced retention time compared with their homoduplex counterparts.

The two techniques applied for the analysis of exons 10 and 11 in this study (that is, PTT and heteroduplex analysis) have been used in two groups of 100 patients with early onset breast cancer and they yielded a similar efficiency in mutation detection. In addition, DHPLC and heteroduplex analysis detected the same mutations when used as primary screening strategies (data not shown).

For cases in group B, BRCA2 mutations previously described in EPC cases were searched using heteroduplex analysis of two PCR fragments encompassing nucleotides 2138-2888, to detect the 2458insT mutation described by Goggins and colleagues, ${ }^{15}$ and nucleotides 5578-6354 to detect 6076delGTTA, 6158insT, and 6174delT mutations. ${ }^{15-17}$

\section{Statistical analysis}

The proportion of BRCA2 mutations and exact $95 \%$ confidence interval (CI) were computed and compared with those described in the literature either applying Fisher's exact test, when $20 \%$ or more of the cells had expected counts of less than 5, or Yates' correction. Results were considered significant at the two sided $\mathrm{p}=0.05$ level.

\section{RESULTS}

Family and personal history of cancer among EPC cases Forty eight of 165 (29.7\%) EPC cases interviewed reported a family history of cancer in a first degree relative; in 20 additional cases such information was not available. Of the 48 patients, 34 had only one, 11 had two, and three reported three first degree relatives with cancer. Table 1 summarises the distribution of cancers in patients' relatives according to tumour site. The most common tumours were from the stomach, breast, colorectum, lung, abdomen (non-specified), and pancreas. Three per cent of cases $(5 / 165)$ reported having a relative with pancreatic cancer. As also shown in table 1 , there were only minor differences in the family history of cancer when comparing patients with EPC and patients belonging to other diagnostic groups from the PANKRAS II study.

Twenty two cases with EPC and a history of familial aggregation of cancer (group A) and 56 cases without such a history who were matched for age, sex, and hospital (group B) were studied further. The number of cases from group B matched to each case from group A ranged from one to three depending on availability. Because EPC is commonly diagnosed in patients with advanced age who are in a poor physical condition, an attempt was made to validate the information obtained from patients. The original information on family history of cancer obtained by personal interviews could not be validated in $24 / 78$ cases (31\%). In $37 / 54$ cases (69\%), the same information was obtained from the original questionnaire and by telephone interview. In 17 additional cases (31\%), novel information on cancer family history was obtained by telephone interview: in seven this information led to a change in group classification (13\%). Based on the results of the validation study, the groups were redefined: group $\mathrm{A}^{\text {val }}$ included 24 $(22-3+5)$ cases and group $B^{\text {val }}$ included $54(56-5+3)$ patients. The original interview information was considered to be valid in cases for whom a telephone interview could not be performed.

To allow a better comparison with other published series, we classified cases as in a recent study from Canada ${ }^{17}$ : none of the 
Table 1 Summary of the distribution of cancers in relatives of pancreatic cancer patients according to tumour site*

\begin{tabular}{|c|c|c|c|c|c|c|}
\hline \multirow{3}{*}{$\begin{array}{l}\text { Family history of can } \\
\text { Unknown }\end{array}$} & \multicolumn{2}{|c|}{$\begin{array}{l}\text { Pancreas } \\
(n=185)\end{array}$} & \multicolumn{2}{|c|}{$\begin{array}{l}\text { EBSC } \\
(n=128)\end{array}$} & \multicolumn{2}{|c|}{$\begin{array}{l}\text { Other } \\
\text { diagnosest } \\
(n=318)\end{array}$} \\
\hline & cer & & & & & \\
\hline & 20 & & 5 & & 31 & \\
\hline Yes & 48 & $(30 \%)$ & 42 & $(34 \%)$ & 74 & $(25 \%)$ \\
\hline No & 117 & (70\%) & 81 & $(66 \%)$ & 215 & $(75 \%)$ \\
\hline \multicolumn{7}{|l|}{ Tumour siteł } \\
\hline Stomach & 7 & & 7.3 & & 5.9 & \\
\hline Breast & 5 & & 5.7 & & 3.5 & \\
\hline Colorectal & 4.2 & & 3.3 & & 2.1 & \\
\hline Lung+pleura & 4.2 & & 6.5 & & 2.1 & \\
\hline Abdominal| & 3.6 & & 1.6 & & 1.4 & \\
\hline Pancreas & 1.8 & & 0.8 & & 1.0 & \\
\hline Liver+EBSC & 1.8 & & 5.7 & & 1.4 & \\
\hline Oesophagus & 1.8 & & 0 & & 0.7 & \\
\hline Prostate & 1.8 & & 0.8 & & 1.7 & \\
\hline Unknown & 1.8 & & 4.9 & & 3.1 & \\
\hline Head and neck & 1.2 & & 3.3 & & 2.1 & \\
\hline Haematopoietic & 1.2 & & 1.6 & & 2.1 & \\
\hline Bladder & 1.2 & & 0 & & 0.3 & \\
\hline Brain & 0.6 & & 1.6 & & 0.7 & \\
\hline Female genital & 0.6 & & 0.8 & & 3.8 & \\
\hline Bone & 0 & & 0 & & 1.0 & \\
\hline Skin & 0 & & 1.6 & & 0 & \\
\hline Kidney & 0 & & 0.8 & & 0.3 & \\
\hline \multirow{2}{*}{$\begin{array}{l}\text { Total relatives with } \\
\text { cancer }\end{array}$} & & & & & & \\
\hline & 65 & & 57 & & 96 & \\
\hline
\end{tabular}

*Data obtained from questionnaire completed by patients. †These diagnoses include: non-malignant diseases of the pancreas ( $n=166$, including 119 chronic pancreatitis), benign biliary disorders $(n=54)$, other benign pathologies $(n=22)$, and other malignancies $(n=47)$.

$\ddagger$ Percentage of cases

INon-specified.

EBSC, extrabiliary system cancer.

patients reported a history of FAMMM, one case reported an inherited breast cancer syndrome, three cases fulfilled the criteria for hereditary non-polyposis colon cancer syndrome, and six cases reported familial pancreatic cancer. Overall, $14.5 \%$ of cases had a history of familial aggregation of cancer (95\% CI 9.5-20.9\%) compared with $27 \%(27 / 102)$ in the series of Lal et al (95\% CI $18.2-36.1 \%){ }^{17}$

Among patients in group $\mathrm{A}^{\mathrm{val}}, 14$ were male and 10 were female; median age was 66.5 years and only one case was $<40$ years old at diagnosis. Six cases (3.6\%) had one relative with EPC. Nine cases had a first degree relative with breast cancer. In $2 / 6$ relatives with breast cancer from whom information was available, the tumour was diagnosed before age 40 years. Ovarian cancer was not reported in any of the cases' relatives. More detailed information regarding the distribution of tumours among relatives from patients included in groups $\mathrm{A}^{\text {val }}$ and $\mathrm{B}^{\mathrm{val}}$ is shown in table 2 .

\section{BRCA2 mutational analysis}

Molecular analysis was performed with DNA from 23 of 24 EPC cases belonging to group $\mathrm{A}^{\text {val }}$. The entire BRCA2 coding sequence from 11 cases was analysed and no mutations were found. This included eight patients reporting a relative with breast cancer, two patients with a relative with pancreatic cancer, and one with two relatives affected by other tumours. More than $80 \%$ of the BRCA2 coding sequence was analysed in 12 additional cases and no mutations were identified. Among them, three had a relative with pancreatic cancer, one had a relative with breast cancer, and eight had two relatives with other tumours.

DNA from matched cases without a familial history of cancer (group $\mathrm{B}^{\text {val }}$ ) was used to screen for the BRCA2 gene mutations (2458insT, 6076delGTTA, 6158insT, and 6174delT) previ-
Table 2 Distribution of tumours in relatives of pancreatic cancer patients according to the presence (group $A^{\text {val }}$ ) or absence (group $B^{\text {val }}$ ) of familial cancer aggregation*

\begin{tabular}{lll}
\hline Tumour site & Group $^{\text {val }}(n=24)$ & Group $^{\text {val }}(n=54)$ \\
\hline Breast & 9 & 0 \\
Pancreas & 6 & 0 \\
Stomach & 5 & 5 \\
Lung+pleura & 5 & 0 \\
Colorectal & 3 & 4 \\
Prostate & 3 & 2 \\
Liver+EBSC & 3 & 1 \\
Abdominal $\dagger$ & 2 & 0 \\
Oesophagus & 2 & 0 \\
Head and neck & 2 & 1 \\
Brain & 1 & 0 \\
Female genital & 1 & 3 \\
Haematopoietic & 0 & 1 \\
Bladder & 0 & 1 \\
\hline
\end{tabular}

*Data obtained from questionnaire completed by patients. †Non-specified.

EBSC, extrabiliary system cancer.

ously reported in patients with EPC unselected for the presence of a family history of cancer. ${ }^{14-16}$ Screening was conducted for 49 of 54 cases. No mutations were detected in the fragment encompassing nucleotides $2138-2888(n=39)$; in 10 cases, difficulties were encountered in amplifying this fragment. Analysis of another BRCA2 fragment (nucleotides 5578-6354) was performed with DNA from 49 cases although in one a PCR product was not successfully obtained. A rare missense variant (T5868G $>$ Asnl880Lys) introducing an amino acid change 11 residues downstream of the core sequence of BRC6 repeat ${ }^{23}{ }^{24}$ was detected. This variant, which was found in a 59 year old male with an adenocarcinoma with a history of tobacco and alcohol consumption, has been reported nine times in the Breast Cancer Information Core database (http://www.nhgri.nih.gov/Intramural research/Lab transfer/Bic/), mainly in individuals of African origin. Mutations previously described in EPC were not found in any of the cases.

\section{DISCUSSION}

A detailed analysis of somatic genetic alterations associated with EPC has paved the way towards the study of the role of hereditary factors in this tumour. ${ }^{9-10}{ }^{12-1725}$ Our study was restricted to the genetic analysis of $B R C A 2$ because mutations in the p16 ${ }^{\mathrm{INK} 4 \mathrm{~A}}$ gene have been reported only among EPC cases with a history of familial melanoma and none of the patients from our series had a personal or family history of this tumour.

Several studies of breast cancer families have suggested an increased incidence of EPC in association with germline $B R C A 2$ mutations. An excess of EPC was reported among families with $B R C A 2$ associated breast cancer. ${ }^{12}{ }^{13}$ In families of Ashkenazi Jewish descent, the existence of a relative with EPC was a significant predictor of BRCA2 mutations ${ }^{14}$ and a large study of cancer risks among $B R C A 2$ mutation carriers showed a relative risk for pancreatic cancer of $3.51 .{ }^{25}$ Other investigators have not found an excess of EPC associated with BRCA2 mutations. ${ }^{26}{ }^{27}$ In none of the studies referred to above were the actual EPC cases studied and, therefore, the assumption was made that they were carriers of the breast cancer associated $B R C A 2$ mutation.

The relevance of BRCA2 mutations in EPC has also been analysed by directly studying patients with this tumour. Goggins et al reported a 7.3\% (3/41) prevalence of BRCA2 germline mutations in cases with apparently sporadic EPC, including 10 
EPC derived cell lines, and Ozçelik et al found a prevalence of $4.9 \%(2 / 41)$ in a series of unselected consecutive patients. ${ }^{16}$ The best characterised series comprised 102 unselected patients with histologically verified EPC who were classified according to defined criteria for various inherited cancer syndromes, age at diagnosis, or a history of multiple cancers. ${ }^{17}$ Thirty eight cases considered of high or intermediate risk underwent $B R C A 2$ analysis using a variety of methods and three mutations were identified. Six of the eight mutations detected in these three studies were 6174delT, a mutation derived from a single ancestral haplotype among Ashkenazi Jewish individuals. ${ }^{28}$ In the study of Lal et al, 14 of 102 cases were of Jewish descent. This value is much higher than that present in the general population of Ontario $(2 \%)$ and is likely to reflect referral patterns at the study centres. ${ }^{17}$ In that series, all three cases with the 6174delT mutation were of Ashkenazi Jewish descent. In previous series from Ontario, the 6174delT mutation was found in 4/39 individuals of Jewish origin with EPC versus 0/55 non-Jewish individuals with EPC, ${ }^{15}{ }^{16}$ a prevalence significantly higher than that found in our series $(0 / 71)$ $(\mathrm{p}=0.027)$. Most BRCA2 mutations among patients with EPC have been reported among patients of Jewish descent and a contributing role for other susceptibility gene loci overrepresented in this population cannot be ruled out.

This work has addressed a number of problems that merit consideration. Serious referral biases are unlikely because our study was conducted in general hospitals that are not specialised in the management of EPC. Cases were prospectively recruited and represent the spectrum of the disease as they were included regardless of the cytohistological confirmation of EPC. A panel of experts reviewed all cases in order to reach a consensus diagnosis. ${ }^{1921}$ Information on family history of cancer was obtained directly from $89 \%$ of cases and was subsequently validated in $70 \%$ of cases analysed for BRCA2 mutations: a change of category (presence $v$ lack of family history of cancer) occurred in only $13 \%$ of cases.

Regarding the familial aggregation of cancer, our series contained a lower proportion of high/intermediate risk familial cancer cases, as defined by Lal et al. This may be due to differences in ethnic background or to referral biases, as discussed by Lal and colleagues. ${ }^{17}$ The prevalence of EPC in a first degree relative was also lower in our series than in other reports. ${ }^{5-7}$ Nevertheless, difficulties in the diagnosis of EPC and misclassification as "abdominal non-specified neoplasm" may partly account for these differences.

In our series, the prevalence of germline BRCA2 mutations was $0 / 23$ for cases with familial aggregation of cancer in whom most of $B R C A 2$ was analysed. Among all cases for which the previously reported $B R C A 2$ germline mutations associated with EPC were analysed, a mutation was identified in 1/71 cases. While the numbers are relatively small, and we did not analyse the entire BRCA2 coding sequence in all cases, our findings suggest that the prevalence of the previously described EPC associated germline BRCA2 mutations is fairly low among Spanish patients with apparently sporadic EPC (1/71). The absence of the 6174delT mutation in our study is likely to reflect the lack of individuals of Ashkenazi Jewish origin in the group of patients studied.

Our data are in agreement with the proposed notion that in EPC, mutations in BRCA2 are not associated with young age at diagnosis and a strong familial aggregation of cancer. ${ }^{15-17}$ The only mutation detected in our series was in a 59 year old patient whose seven first degree relatives lacked a history of cancer. The prevalence of preneoplastic lesions in the pancreas of three cases with EPC harbouring a germline BRCA2 mutation has been reported to be similar to that found in patients with sporadic tumours. This finding would be in agreement with the low penetrance of BRCA2 germline mutations and their lack of association with a younger age at diagnosis. ${ }^{29}$

$B R C A 2$ germline mutations confer an increased risk for the development of EPC. Our study supports the notion that their public health relevance depends on the prevalence of $B R C A 2$ germline mutations in the study population. The 6174delT mutation appears to be rather infrequent among patients with familial breast cancer in the South of Europe ${ }^{30-32}$ and it is likely to have a very low prevalence in the general population. Screening patients with EPC for germline BRCA2 mutations may be of clinical value to identify relatives at risk of developing this tumour in selected patient populations, such as the Ashkenazi Jewish or in familial EPC kindreds. ${ }^{33}$ However, it is less likely that such screening will be useful in populations with a low prevalence of BRCA2 germline mutation carriers.

\section{APPENDIX}

Centres and members of the PANKRAS II study group Institut Municipal d'Investigació Mèdica, Universitat Autònoma de Barcelona (Coordinating Centre): $\mathrm{F} \mathrm{X} \mathrm{Real',} \mathrm{M}$ Porta', N Malats' ${ }^{2}$, E Carrillo ${ }^{3}$, I Cortès ${ }^{3}$, E Fernandez ${ }^{3}$, L Gavaldà $^{3}$, J L Piñol ${ }^{3}$ J Alguacil, A García de Herreros, A Maguire, A Serrat, M Soler, M Torà. Hospital General de Elche: A Carrato², E Gómez ${ }^{3}$, V Barberà, J M Barón, M de Diego, R Guaraz, F J Lacueva, J A Maruenda, A Orduña, J Ruiz, C Sillero, A Teruel. Hospital del Mar, Barcelona: M Andreu $^{2}$, J M Corominas ${ }^{4}$, S Coll, M Conangla, J M Gubern, T Maristany, A Panadès, R Solà, F Tous. Hospital de Son Dureta, Mallorca: J Rifà ${ }^{2}$, M Marrugat ${ }^{3}$, J Calafell, P de Miguel, J Forteza, N Matamoros, A Obrador, O Pons, C Saus, T Terrasa. Hospital de la Vall d'Hebron, Barcelona: L Guarner², A Alvarez, J Bellmunt, I de Torre, M García, E Murio, A Nadal, V Puig-Diví, N Tallada. Hospital Mútua de Terrassa: A Salas² 4, E Cugat, J C Espinós, E García Olivares, M García.

'Principal investigator, ${ }^{2}$ Centre Coordinator-Investigator, ${ }^{3}$ Monitor, ${ }^{4}$ Reference pathologist.

\section{ACKNOWLEDGEMENTS}

FXR wishes to dedicate this paper to the memory of his mother. We thank R Santed for help in the validation of the questionnaires on family history of cancer and Dr J Benítez for valuable discussions and for providing unpublished data. We also thank the members of the PANKRAS II study group for their contribution to the study and the following colleagues who participated in various aspects of the study: J Alguacil, V Barberá, P Barbas, S Costafreda, L Español, E Fernandez, JL Piñol, L Ruiz, and M Soler. This work was supported in part by research grants from Fondo de Investigación Sanitaria (92/0007, 95/0017 and 97/1138), CIRIT (Generalitat de Catalunya) (SGR 00241 and SGR 00078), Ministerio de Ciencia y Tecnología (CICYT, SAF 2000-0097), Fundación Salud 2000, and MSD Spain.

\section{Authors' affiliations}

F X Real, Unitat de Biologia Cel.lular i Molecular, Institut Municipal d'Investigació Mèdica, Universitat Pompeu Fabra, Barcelona, Spain N Malats, Grup de Recerca en Epidemiologia Clínica I Molecular del Càncer, Institut Municipal d'Investigació Mèdica, Universitat Pompeu Fabra, Barcelona, Spain

G Lesca, S Chopin, G M Lenoir, International Agency for Research on Cancer, Lyon, France

M Porta, Grup de Recerca en Epidemiologia Clínica I Molecular del Càncer, Institut Municipal d'Investigació Mèdica, Universitat Pompeu Fabra, Barcelona, Spain and Universitat Autònoma de Barcelona, Barcelona, Spain

O Sinilnikova, Laboratoire de Génétique, Hôpital Edouard Herriot, Lyon, France

\section{REFERENCES}

1 American Gastroenterology Association position statement on epidemiology, diagnosis, and treatment of pancreatic ductal carcinoma. Gastroenterology 1999;117:1463-84.

2 Weiderpass $E$, Partanen T, Kaaks R, et al. Pancreatic cancer: Occurrence, trends, and environmental etiology. A review. Scand J Work Environ Health 1999;24: 165-74.

3 Anderson KE, Potter JD, Mack TM. Pancreatic cancer. In: Schottenfeld D. Fraumeni JF Jr, eds. Cancer epidemiology and prevention, 2nd ed. New York: Oxford University Press, 1996:725-71.

4 Hruban RH, Petersen GM, Goggins M, et al. Familial pancreatic cancer. Ann Oncol 1999;10(suppl 4):69-73. 
5 Fernandez E, La Vecchia C, D'Avanzo B, et al. Family history and the risk of liver, gallbladder and pancreatic cancer. Cancer Epidemiol Biomark Prev 1994;3:209-12

6 Ghadirian P, Boyle P, Simard A, et al. Reported family aggregation of pancreatic cancer within a population-based case-control study in the francophone community in Montreal, Canada. Int J Pancreatol 1991;10:183-96.

7 Silverman DT, Schiffman M, Everhart J, et al. Diabetes mellitus, other medical conditions and familial history of cancer as risk factors for pancreatic cancer. Br J Cancer 1999:80:1830-7.

8 Efthimiou E, Cmogorac-Jurcevic T, Lemoine NR, et al. Inherited predisposition to pancreatic cancer. Gut 2001;48:143-7.

9 Huhussian CJ, Struewing JP, Goldstein AM, et al. Germline p16 mutations in familial melanoma. Nat Genet 1994:8:15-21.

10 Whelan AJ, Bartsch D, Goodfellow PJ. Brief report: A familial syndrome of pancreatic cancer and melanoma with a mutation in the CDKN2 tumor-suppressor gene. N Engl J Med 1995;33:975-7.

11 Schutte M, da Costa LT, Hahn SA, et al. Identification by representational difference analysis of a homozygous deletion in pancreatic carcinoma that lies within the BRCA2 region. Proc Natl Acad Sci USA 1995:92:5950-4

12 Thorlacius S, Olafsdottir G, Tryggvadottir L, et al. A single BRCA2 mutation in male and female breast cancer families from lceland with varied cancer phenotypes. Nat Genet 1996;13:117-19.

13 Phelan CM, Lancaster JM, Tonin $P$, et al. Mutation analysis of the BRCA2 gene in 49 site-specific breast cancer families. Nat Genet 1996; 13:120-2.

14 Tonin PN, Mes-Masson AM, Futreal PA, et al. Founder BRCA1 and BRCA2 mutations in French Canadian breast and ovarian cancer families. Am J Hum Genet 1998;63:1341-51.

15 Goggins M, Schutte M, Lu J, et al. Germline BRCA2 gene mutations in patients with apparently sporadic pancreatic carcinomas. Cancer Res 1996;56:5360-4.

16 Ozçelik H, Schmocker B, Di Nicola N, et al. Germline BRCA2 6174delT mutations in Ashkenazi Jewish pancreatic cancer patients. Nat Genet 1997; 16:17-8

17 Lal G, Liu G, Schmocker B, et al. Inherited predisposition to pancreatic adenocarcinoma: role of family history and germline pl6, BRCA 1, and BRCA2 mutations. Cancer Res 2000;60:409-16.

18 Porta M, Malats N, Guarner L, et al. Association between coffee drinking and K-ras mutations in exocrine pancreatic cancer. J Epidemiol Comm Health 1999;53:702-9.
19 Porta M, Costafreda S, Malats N, et al. Validity of the hospital discharge diagnosis in epidemiologic studies of biliopancreatic pathology. Eur J Epidemiol 2000;16:533-41.

20 Porta M, Malats N, Jariod M, et al. Serum concentrations of organochlorine compounds and K-ras mutations in exocrine pancreatic cancer. Lancet 1999;354:2125-9.

21 Soler M, Porta M, Malats N, et al. Learning from case-reports: diagnostic issues in an epidemiologic study on pancreatic cancer. J Clin Epidemiol 1998;51:1215-21.

22 Serova OM, Mazoyer S, Puget N, et al. Mutations in BRCAl and BRCA2 in breast cancer families: are there more breast cancer-susceptibility genes? Am J Hum Genet 1997;60:486-95

23 Bork P, Blomberg N, Nilges M. Internal repeats in the BRCA2 protein sequence. Nat Genet 1996:13:22-3.

24 Bignell G, Micklem G, Stratton MR, et al. The BRC repeats are conserved in mammalian BRCA2 proteins. Hum Mol Genet 1997;6:53-8.

25 The Breast Cancer Linkage Consortium. Cancer risks in BRCA2 mutation carriers. J Natl Cancer Inst 1999:91:1310-6.

26 Johansson $\mathrm{O}$, Loman $\mathrm{N}$, Moller T, et al. Incidence of malignant tumours in relatives of $B R C A 1$ and $B R C A 2$ germline mutation carriers. Eur J Cancer 1999;35:1248-57.

27 Couch FJ, Farid LM, DeShano ML, et al. BRCA2 germline mutations in male breast cancer cases and breast cancer families. Nat Genet 1996;13:123-5.

28 Neuhausen SL, Godwin AK, Gershoni-Baruch R, et al. Haplotype and phenotype analysis of nine recurrent BRCA2 mutations in 111 families: results of an international study. Am J Hum Genet 1998;62:1381-8.

29 Goggins M, Hruban RH, Kern SE. BRCA2 is inactivated late in the development of pancreatic intraepithelial neoplasia: evidence and implications. Am J Pathol 2000;156:1767-71.

30 Díez O, Osorio A, Robledo $M$, et al. Prevalence of BRCA1 and BRCA2 Jewish mutations in Spanish breast cancer patients. Br J Cancer 1999;79:1302-3.

31 Gomendio B, Silva JM, García JM, et al. Low incidence of germline BRCA2 gene mutations among Spanish breast cancer patients. Oncology 1999;57:173-4

32 Díez O, Cortes J, Domenech $M$, et al. BRCA2 germ-line mutations in Spanish male breast cancer patients. Ann Oncol 2000;1 1:81-4.

33 Tersmette AC, Petersen GM, Offerhaus GJA, et al. Increased risk of incident pancreatic cancer among first-degree relatives of patients with familial pancreatic cancer. Clin Cancer Res 2001;7:738-44. 